\title{
Combining meteorological radar and network of rain gauges data for space-time model development
}

\author{
V. Pastoriza ${ }^{1, *, \dagger}$, A. Núñez ${ }^{2}$, F. Machado ${ }^{1},{ }_{\text {P. Mariño }}{ }^{1}$, F. P. Fontán ${ }^{2}$ \\ and U.-C. Fiebig ${ }^{3}$ \\ ${ }^{1}$ Electronic Technology Department, University of Vigo, 36310, Vigo, Spain \\ ${ }^{2}$ Signal Theory and Communications Department, University of Vigo, 36310, Vigo, Spain \\ ${ }^{3}$ German Aerospace Center (DLR), Institute for Communications and Navigation, D-82230, Wessling, Germany
}

\begin{abstract}
SUMMARY
Technological developments and the trend to go higher and higher in frequency give rise to the need for true space-time rain field models for testing the dynamics of fade countermeasures. There are many models that capture the spatial correlation of rain fields. Worth mentioning are those models based on cell ensembles. However, the rain rate fields created in this way need the introduction of the time variable to reproduce their dynamics. In this paper, we have concentrated on addressing the time domain effects while we have relied on existing spatial rain field models for creating initial fields, which are propagated (advected) according to proposed models and assumptions, some of which have been drawn from a combined use of a concurrent weather radar and a network of rain gauges. The dynamic modeling presented simulates the advection of a synthetically generated rain field according to dynamic, spatially correlated advection fields extracted from the analysis of weather radar images. Experimental data and model fits have been presented as well. Further ideas on how to improve the realism of the generated dynamic fields have also been presented. Furthermore, the limitations of radar data, especially those related to their limited time resolution, for the required space-time models have been pointed out. These can be overcome by using data from a network of rain gauges. However, it is important to be aware of the similarities and differences between these two sources. A comparative study of these two data sets has also been presented. Copyright (C) 2009 John Wiley \& Sons, Ltd.
\end{abstract}

KEY WORDS: weather radar; network of rain gauges; rain rate space-time model; radiocommunication

\section{INTRODUCTION}

A current objective in the modeling of rain-induced propagation effects for radiocommunication applications above about $10 \mathrm{GHz}$ is the development of space-time models of rain fields, usable in dynamic simulators capable of reproducing both the time autocorrelation and the space cross-correlation properties of rain-induced attenuation [1-5]. Unlike in hydrology and

\footnotetext{
*Correspondence to: V. Pastoriza, Electronic Technology Department, University of Vigo, 36310, Vigo, Spain.

†E-mail: vpastoriza@uvigo.es
} 
similar applications, in radio, the effect of rain needs to be considered on an instantaneous basis. Thus, very short integration times are employed to estimate the rain intensity or rain rate, typically of $1 \mathrm{~min}$.

Rain gauge and weather radar are probably the two most widely available sensors used to measure precipitation. However, the knowledge on rainfall fields provided by these two instruments separately does not fulfill the requirements for radiocommunication applications, thus, there is interest in developing methodologies for characterizing and modeling rain fields by merging radar and rain gauge data. In this sense, several proposals have been reported, mainly found in the hydro-meteorological literature. Among those, it is worth mentioning [6-13]. In the work reported here, these references have been taken into account but always bearing in mind the special requirements for radio systems.

In this paper, the characteristics of a concurrent radar plus network of rain gauge experiment are discussed, and the advantages and shortcomings of both sensor types are discussed in the light of the requirements of the space-time models to be developed.

\section{RAIN FIELD MODELING AND REQUIREMENTS}

In this section, the basic features of a space-time rain field model oriented toward the simulation of the dynamics of the attenuation due to rain undergone by several simultaneous radio links at frequencies above $10 \mathrm{GHz}$ are presented. The objective of this section is pointing out the required inputs for developing a model of this type. Here we use the model presented in [14], as an example. The discussions below should put in perspective the type of empirical information required and what can be expected from two similar but, at the same time, very different sources of empirical data: a weather radar and a network of rain gauges.

\subsection{Rain field modeling}

The simulator in [14] starts off with an initial scenario containing rain cells (rain field, RF). This represents the scenario at $n T_{\text {sim }}$ with $n=0$, that is, at the beginning of the simulation, where $T_{\text {sim }}$ is the simulation step, typically, $10 \mathrm{~min}$. An advection field, AF, is generated and applied to this initial RF and to consecutive ones, thus making the rain field advance according to the time-varying AF. The general schematic diagram of this simulator is shown in Figure 1.

This simulator makes a number of underlying assumptions:

- Advection is the only physical process that drives the movement of the rain field. Advection is the variation of a scalar at a given point due to a vector field.

- No rain sources or sinks exist.

- A rain shift or advection vector is assigned to each pixel in the simulated scenario. The rain field is treated as an $M \times N$ image made up of pixels, $1 \times 1 \mathrm{~km}^{2}$ in size. The contents (rain rate) of the $i j$ pixel are shifted by a distance, $\rho_{i j}$, and an angle, $\varphi_{i j}$, which are the results of summing the previous advection vector at time $(n-1) T_{\text {sim }}$ with a newly generated, that is, at time $n T_{\text {sim }}$, increment, $\Delta \rho_{i j}$ and $\Delta \varphi_{i j}$. Adjacent pixels undergo correlated increments. 


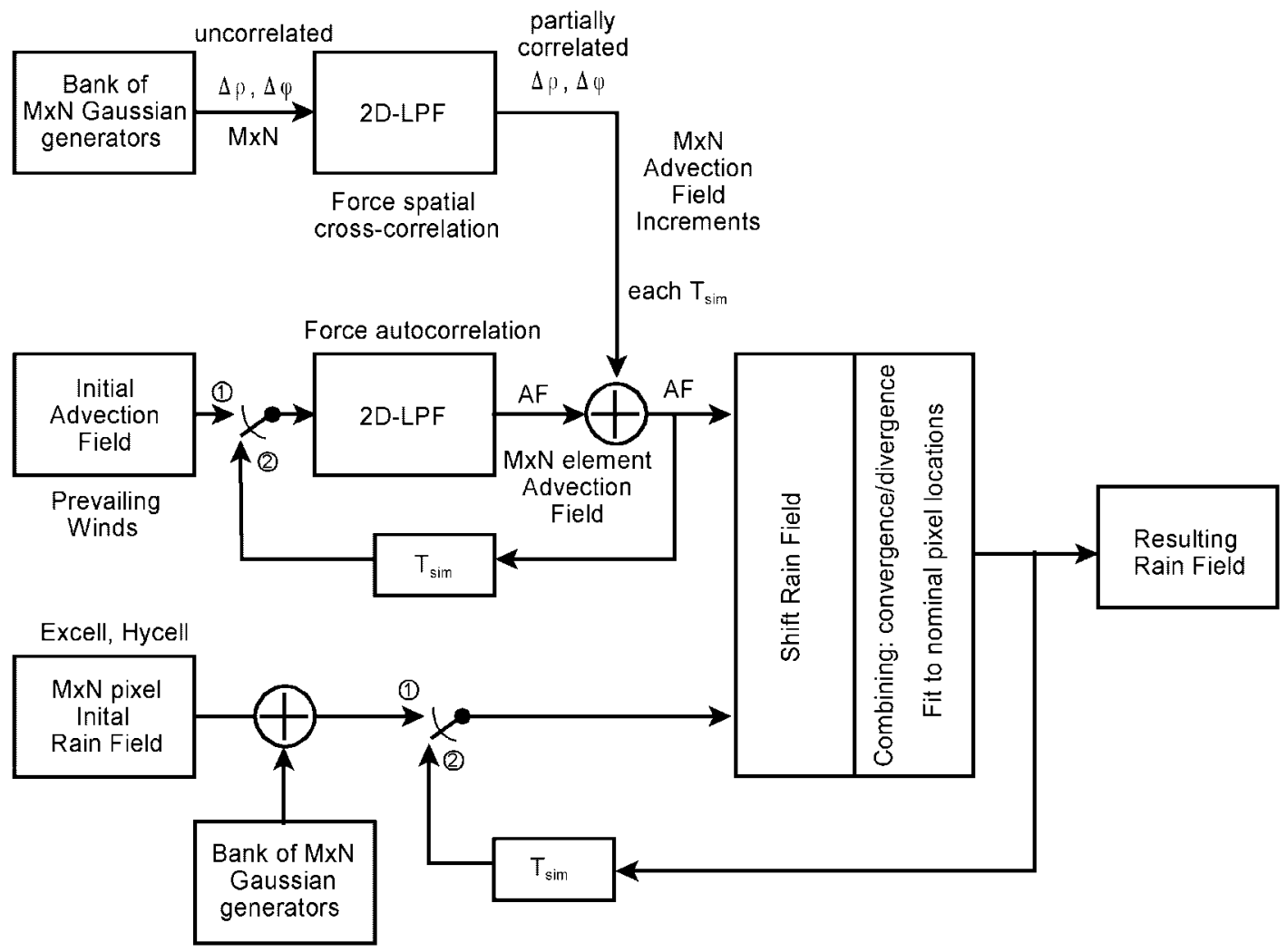

Figure 1. General schematic diagram of the dynamic rain field simulator. Advection field (AF), LPF (2D Low pass filter), $T_{\text {sim }}$ (simulation time step).

- Both the sets of $\mathrm{M} \times \mathrm{N}$ increments, $\Delta \rho_{i j}$ (magnitude) and $\Delta \varphi_{i j}$ (direction), can be described by means of Gaussian distributions with the given spatial cross-correlation and time autocorrelation properties.

2.1.1 Rain field generation. Coming back to Figure 1, the simulator contains three branches converging in a pixel shift and combines the module to produce each new RF image for each $n T_{\text {sim. }}$. At the bottom is the initial rain field, at $n=0$. This RF is generated using well-recognized rain cell models such as Excell [15] or Hycell [16]. Figure 2 illustrates one such exponential cell, where $R_{E}$ is the peak intensity, $a_{E}$ and $b_{E}$ are the distances along the Ox and Oy axes for which the peak decays by a $1 / \mathrm{e}$ factor and $R_{2}$ is the minimum value considered. The initial $\mathrm{RF}$ is created following Goldhirsh's approach [17], where synthetic scenarios with exponential rain cells are generated according to given rules while fitting the yearly cumulative distributions corresponding to the former ITU-R climatic regions. One example of an initial RF is shown in Figure 3. Two main areas can be distinguished in it, one is the overall window and the other is the observation window. In the case of Figure 3, a West-East advection has been assumed. Thus, the observation window is situated at the right of the overall window. The contents of the 


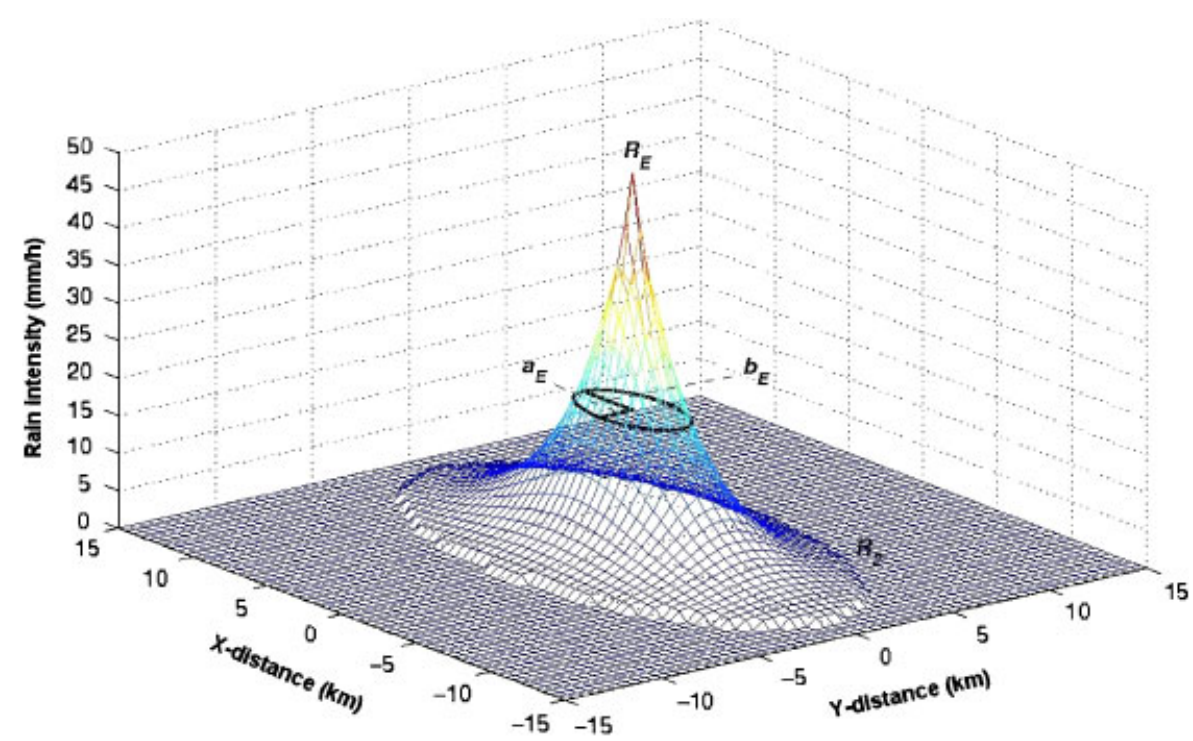

Figure 2. Structure of an exponential cell with parameters: $R_{E}=50 \mathrm{~mm} \mathrm{~h}^{-1}, a_{E}=1.67 \mathrm{~km}, b_{E}=3.34 \mathrm{~km}$ and $R_{2}=1.01 \mathrm{~mm} \mathrm{~h}^{-1}$.

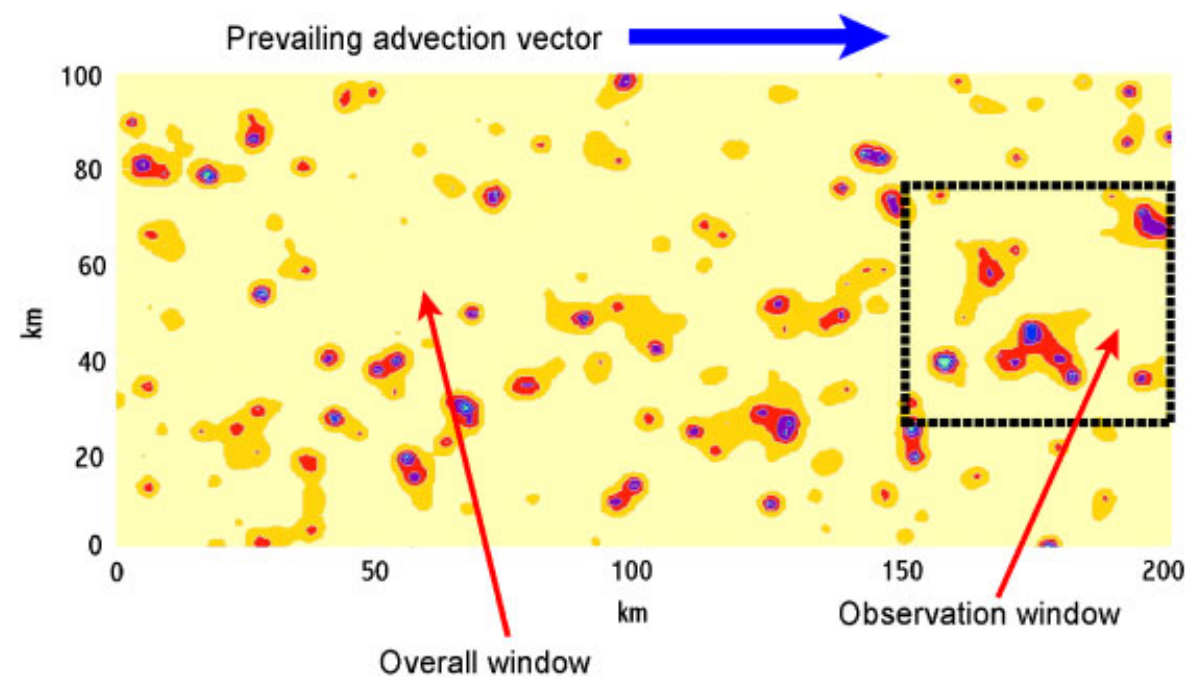

Figure 3. Initial rain field, RF, made up of Excell rain cells [15] of different sizes and intensities, following [17].

overall window will be shifted from left to right during the simulation process at the same time that advection vectors are applied to each pixel at each simulation step and the results combined as discussed below. Once the contents of the overall window have all been shifted right, the 
simulation is finalized. If longer simulation periods need to be simulated, larger overall windows must be created in the first place.

The overall window shall be much larger than the observation window, and will be the only possible origin of rain. The observation window will represent the actual simulated scenario and will be located within the overall window in such a way that the advection process will shift the initial rain cells into the observation window for the duration of the simulated period, for example, $6 \mathrm{~h}$. The observation window, the duration of the simulation and the advection vector will define the size of the overall window or the initial RF (Figure 3). We have to emphasize that the overall window size, when using Goldhirsh's approach, only allows the generation of initial RFs at mid-scale. For this reason, simulation durations will be limited by the size of the overall window and the advection velocity considered.

In the lowest branch in Figure 1, an additive noise source could be optionally added to further increase the realism of the initial RF. One possible way randomizing the initial RF could be using the UVIGO-DLR model, also called two-rain type model, as discussed in [18]. The area of each exponential cell can be sliced into two regions corresponding to the intense and steady rain types, as schematically represented in Figure 4. For those points located on the intense rain areas, samples of this type of rain are drawn with the corresponding generator defined in the model. The same is done for those points on steady rain areas of the cell. Figure 5 illustrates a randomized rain field generated inside a window of $20 \times 20 \mathrm{~km}^{2}$ using the proposed approach. The spatial cross-correlation properties of the new, randomized field are still mostly preserved as the exponential cell structure is used as the basis for the whole randomization process. This option is still under evaluation and requires further in detail analysis.

Also on the lowest branch, the image produced at $n T_{\text {sim }}$ is fed back to be used, together with the advection information, to generate the next RF at $(n+1) T_{\text {sim. }}$. Note that both the initial RF and AF are only used once, that is, both switches in the middle and lower branches are on position 1. After that, both switches are turned to position 2 .

2.1.2. Advection field generation. In the middle branch, the advection information is generated. The AF has been defined in the polar coordinates: $\rho_{i j}$ (magnitude) and $\varphi_{i j}$ (direction) at each $i j$ pixel. The process starts off by defining a general advection trend (prevailing wind) identical at

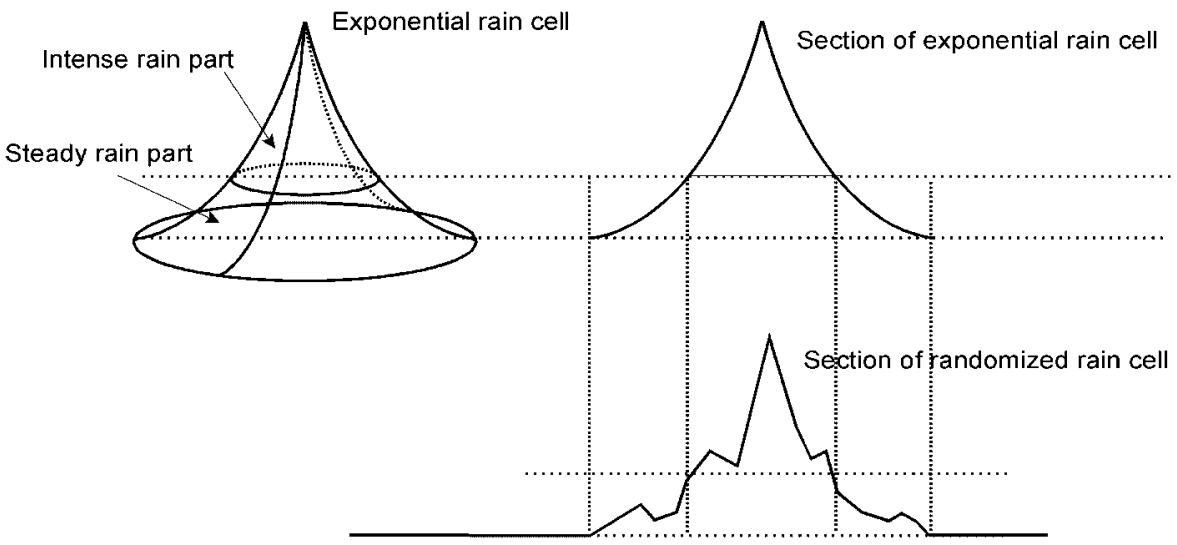

Figure 4. Randomization of an exponential cell by slicing it into two regions with intense and steady rain. 

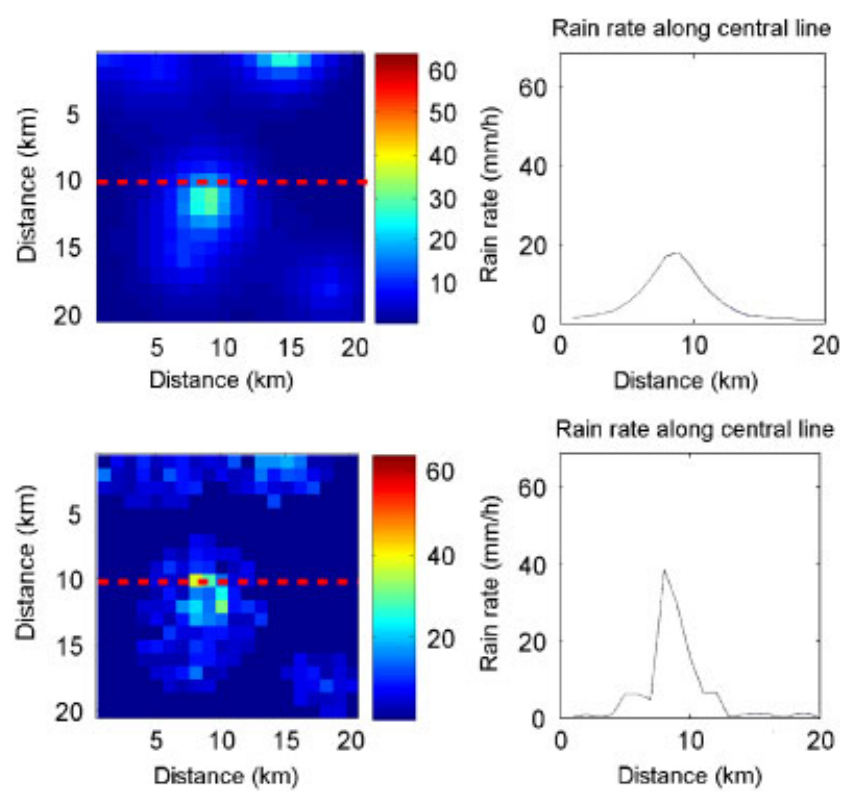

Figure 5. Section of rain field generated with Excell rain cells (top left) and rain rate along central horizontal line (top right). Randomized rain field using two-rain type model (bottom left) and rain rate along central horizontal line (bottom right).

all pixels: $\left(\rho_{\text {initial }}, \varphi_{\text {initial }}\right)$. This is modified by local increments, $\Delta \rho_{i j}$ and $\Delta \varphi_{i j}$. The bi-dimensional low-pass filter in the feedback loop is used to introduce the needed autocorrelation between the advection vectors at $n T_{\text {sim }}$ and $(n+1) T_{\text {sim }}$, that is, the rate of variation of $\rho_{i j}$ and $\varphi_{i j}$.

A two-parameter Weibull distribution, $\mathrm{W}(\alpha, \beta)$, and a normal distribution, $\mathrm{N}(\mu, \sigma)$, have been proposed for $\rho_{\text {initial }}$ and $\varphi_{\text {initial}}$, respectively, in [19-21]. In [22] a value of $42 \mathrm{~km} / \mathrm{h}$ has been proposed for parameter $\alpha$ and 2.36 for $\beta$. This means that the initial velocity has an average of $37.2 \mathrm{~km} / \mathrm{h}$ and that the probability that $\rho_{\text {initial }}$ exceeds $80 \mathrm{~km} / \mathrm{h}$ is only $1 \%$. In [22] a normal distribution for $\varphi_{\text {initial }}$ with parameters $\mu=25^{\circ}$ and $\sigma=65^{\circ}$ has been proposed. These are the distributions used.

Finally, the top branch represents the local advection increments, $\Delta \rho_{i j}$ and $\Delta \varphi_{i j}$. These are first generated according to the two Gaussian distributions fitted to measured advection vectors extracted from the radar images as, for example, those in Figure 6. Several image processing algorithms are available for extracting the advection in the radar images. Two techniques have been mainly used in this work, one called the Optical Flow Technique [23] and the other called the Polynomial Expansion Technique [24].

Such increments have been shown to fit quite well two Gaussian distributions [14] except for the extreme parts of the tails as shown in Figure 7. The bi-dimensional low-pass filter on this branch forces the given spatial cross-correlation properties, which can be modeled by negative exponential or by polynomial functions [14] as in the example of Figure 8. An advection increment field, AIF, is generated for each $n T_{\text {sim. }}$. Figure 8 implies that the spatial correlation properties of the advection increments are isotropic, that is, the spatial correlations of $\Delta \rho$ and $\Delta \varphi$ are independent of the values of $\rho$ and $\varphi$. However, this assumption still needs validation.

Each new rain field, that is, $\operatorname{RF}\left[(n+1) T_{\text {sim }}\right]$ is the result of shifting each pixel in the previous rain field, $\operatorname{RF}\left(n T_{\text {sim }}\right)$, by its corresponding advection field, $\mathrm{AF}$, element $\left(\rho_{i j}, \varphi_{i j}\right)$. After this, the 


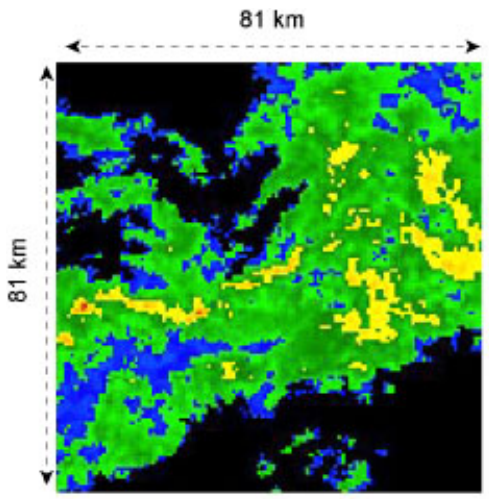

Image at T-1

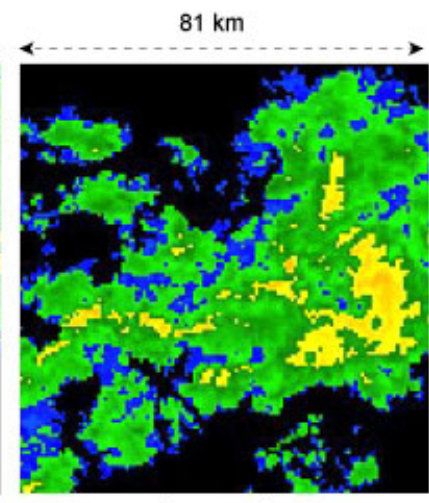

Image at T

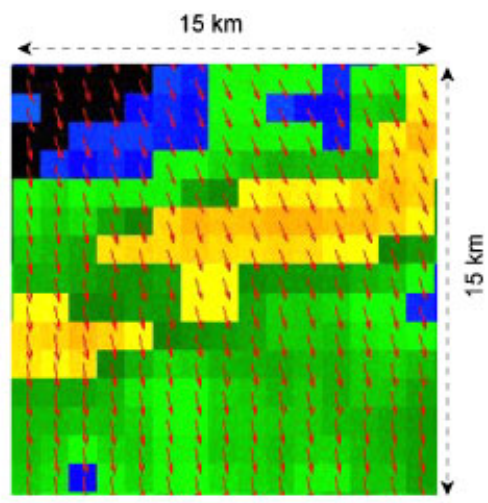

Calculated advection from $T-1$ to $T$

Figure 6. Example of advection information extracted using the Optical Flow Technique [23]. $15 \times 15 \mathrm{~km}^{2}$ central region of overall $81 \times 81 \mathrm{~km}^{2}$ radar image.
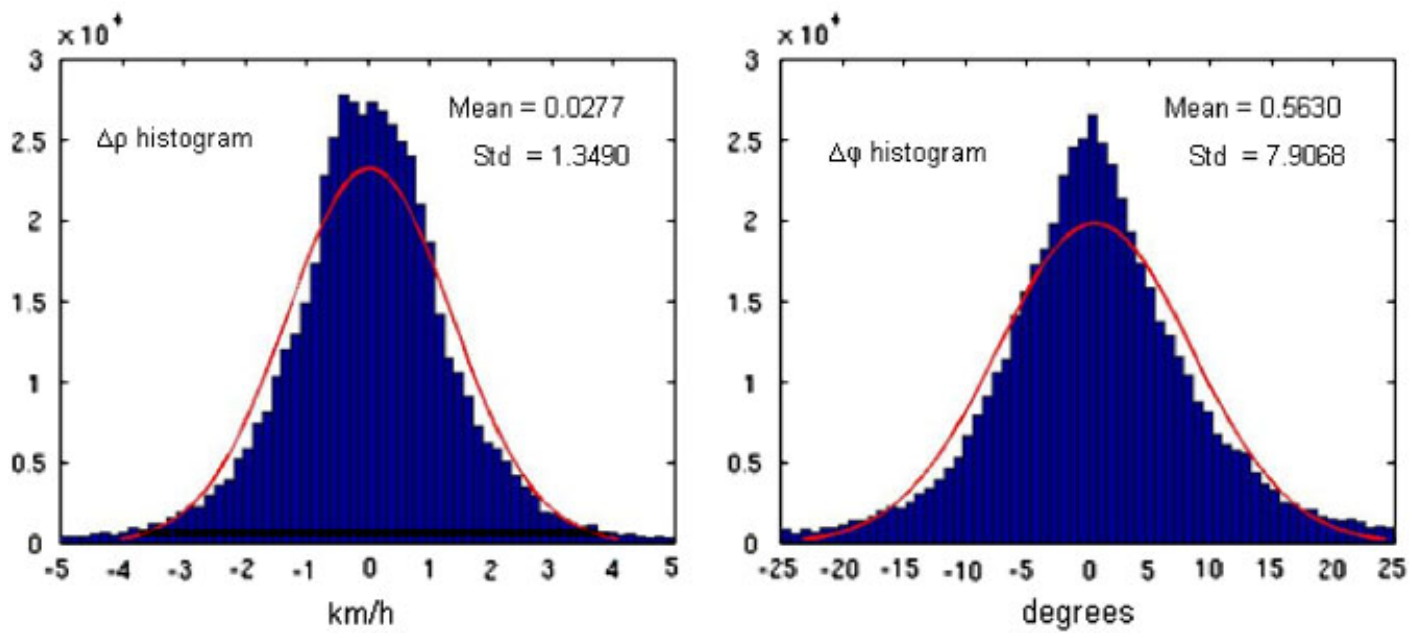

Figure 7. Measured and modeled advection increments [14].

new position of each pixel, in general, will not match up to a nominal pixel position, as shown in Figure 9(a). Thus, its rain rate will be spread out over several pixels. This approach inherently takes into account the pixel convergence and divergence, thus giving rise to locally increasing and decreasing rain rates (although, the overall amount of rain in the image remains constant). This is illustrated in Figure 9(b). This convergence or divergence of pixel rain rates could produce a rearrangement of the total rain in the field including the 'birth' of new cells and the 'death' of existing cells.

\subsection{Requirements}

For creating and parameterizing the above model, rain radar images have been used. The information provided by the radar is updated every 10 min while the pixel size is $1 \times 1 \mathrm{~km}^{2}$. The 

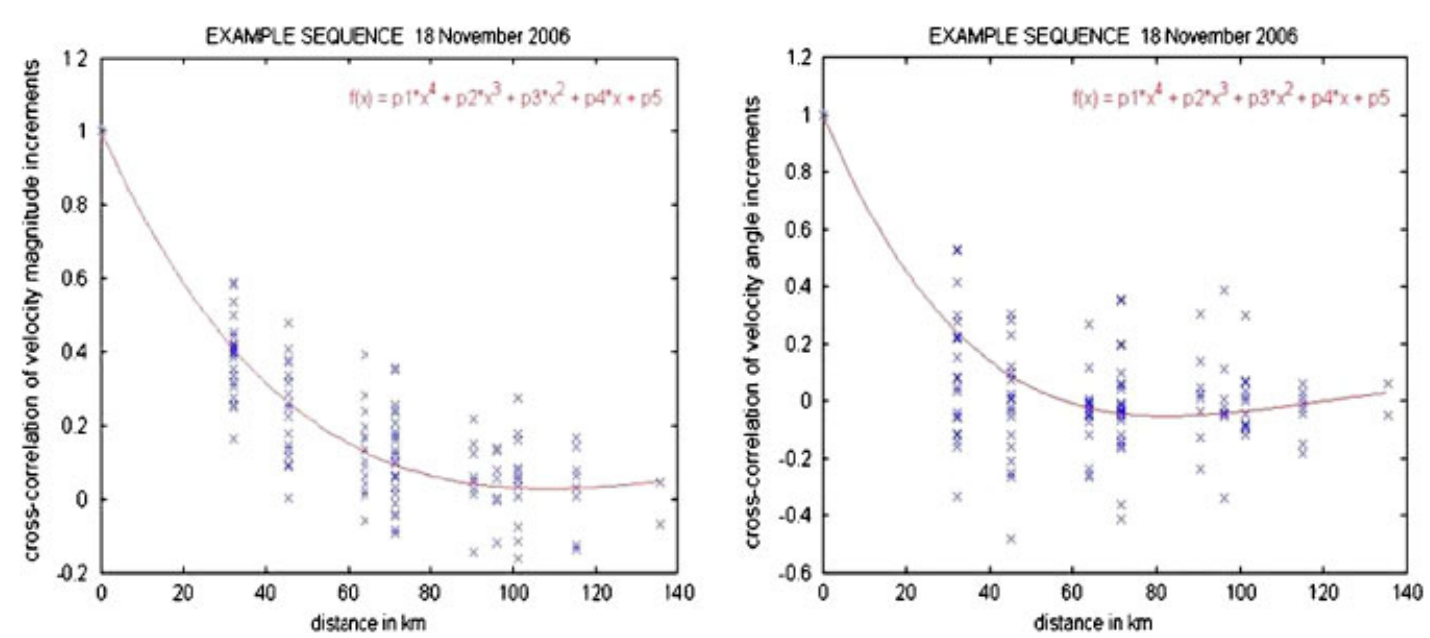

Figure 8. Measured and fitted cross-correlation properties of the advection increments [14].

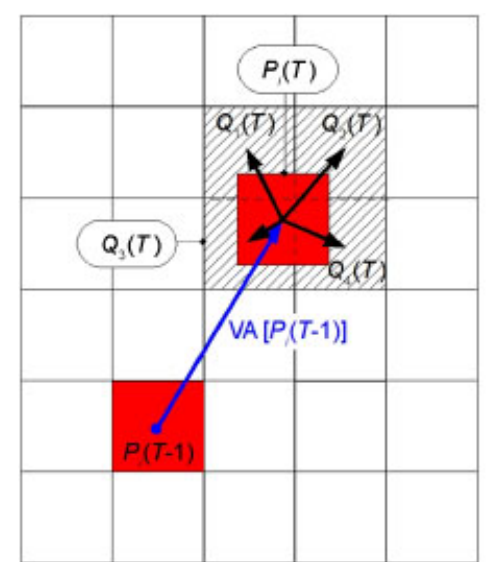

(a)

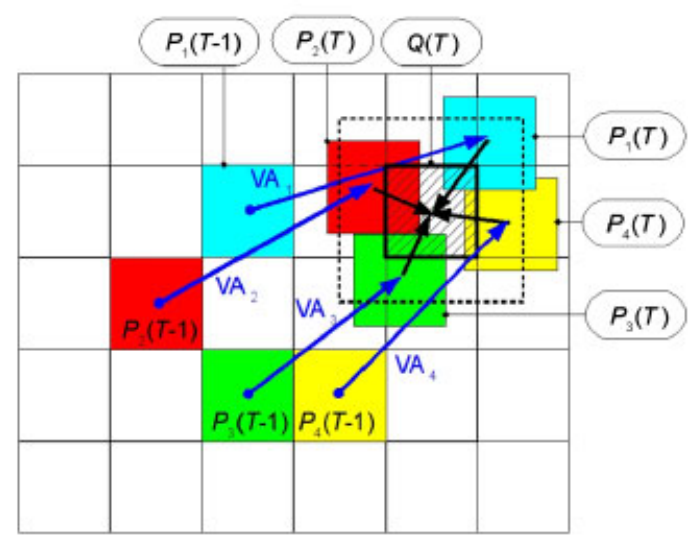

(b)

Figure 9. (a) Owing to advection, the rain rate in a given pixel, $P_{i}$, at time $T-1$ will be shifted and may not match a nominal pixel location. Its rain rate will be spread out over several pixels, $Q_{j}$, at time $T$. (b) Pixels $P_{1}, P_{2}, P_{3}$ and $P_{4}$ at time $T-1$ are shifted to their new position at time $T$. Parts of their respective rain rates are assigned to pixel $Q$ at time $T$.

question arises about whether the above time and space resolutions are sufficiently large for capturing the space-time dynamics of the phenomenon. The extraction of advection increments, $\Delta \rho_{i j}$ and $\Delta \varphi_{i j}$, their distributions and spatial cross-correlation seems to provide coherent results, which have allowed its modeling by using standard distributions and functions. However, it has been observed that the time autocorrelations of the pixel advection increments are uncorrelated for the refresh rate of the radar, that is, $10 \mathrm{~min}$. This leads to the need to look deeper into this point. This also means that, in the current implementation, the bi-dimensional low-pass filter in the middle branch is not implemented. 
It is the opinion of the authors that a dense network of rain gauges may be the appropriate source for characterizing the autocorrelation of the advection vector variations. In addition, such a network can provide more detailed reconstructions of the time evolution of the spatial structure of the rain field.

Below the initial results are presented, where the capabilities of such a network of rain gauges and how they compare with those of the radar are shown. The only limitation being that the size of the images produced in this way will be far smaller. On the positive side, their update rate will be much faster.

In the following sections, the similarities and differences of the data obtained with the two sensors (weather radar and network of rain gauges) are investigated as we try to identify the best suited source of experimental data for extracting the required space-time model parameters.

\section{RADAR-RAIN GAUGE NETWORK COMPARISONS}

\subsection{Data characteristics}

In this section, details of a combined radar and network of rain gauge network are provided together with characteristics of the data obtained from both sources. Plan Position Indicator (PPI), C-Band, Doppler weather radar images are being recorded at Cerceda (Figure 10(a)) in the North-West of Spain $(43.1690 \mathrm{~N}, 8.5261 \mathrm{~W})$. This radar specially focuses on rain fronts coming in from the Atlantic. The images contain reflectivity, $Z$, values in dBZ, where $Z=10 \log _{10}(z)$, with $z$ in $\mathrm{mm}^{6} \mathrm{~m}^{-3}$. The space resolution of the data is $1 \times 1 \mathrm{~km}^{2}$, while the time resolution is $10 \mathrm{~min}$ [14]. In the vicinity of the radar, at distances ranging from 10 to $40 \mathrm{~km}$, a network of 17 tipping bucket rain gauges has been deployed. This network covers an area of roughly $360 \mathrm{~km}^{2}$ (Figure 10 (b)). The gauge catchment area is of $200 \mathrm{~cm}^{2}$, the recordings are carried of with a $1 \mathrm{~s}$ resolution, each tip corresponding to $0.1 \mathrm{~mm}$ of rain.

Although the space and time resolutions of both sources are very different, still a relationship must exist between the measurements carried out with the radar and the rain gauges. Radar reflectivity, $z\left(\mathrm{~mm}^{6} \mathrm{~m}^{-3)}\right.$, can be converted into rain rates, $R\left(\mathrm{~mm} \mathrm{~h}^{-1}\right)$. Several empirical relationships are available in the literature [25]. The expression $z=238 R^{1.5}$ is considered by the radar operators as the most appropriate for the type of rain seen by this radar and is the one

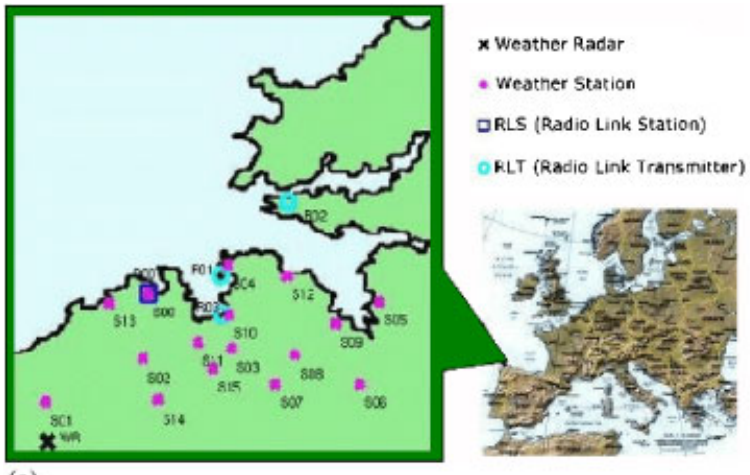

(a)

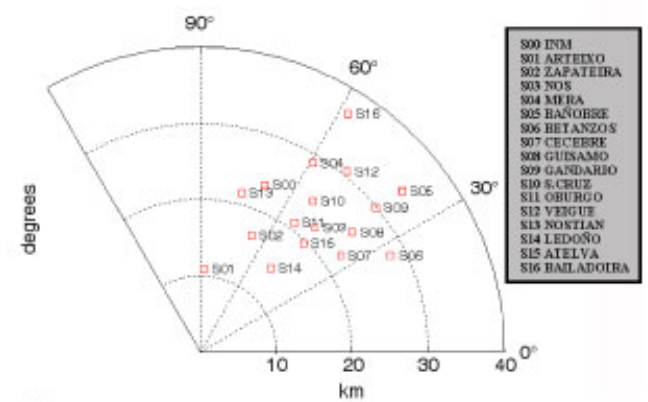

(b)

Figure 10. (a) Rain gauge network and (b) Rain gauge locations as seen from radar. 
used throughout this paper. Still the relationship between the two types of measurements is not straightforward as will be shown next. Currently, work is in progress on the dynamic calibration of the $z-R$ relationship from these joint radar-rain gauge rainfall observations.

\subsection{Generation of rain field images using the network of rain gauges}

Figure 11 illustrates a radar image, its contoured version indicating the location of the 17 gauges and, finally, a contoured image created from the network of rain gauge data. The images are not totally matching, but this is to be expected due to the different nature of the sensors. Below, the differences and similarities in the information gathered with these two data sources are further illustrated. However, it must be pointed out that while the radar provides us with one image every $10 \mathrm{~min}$, the network of rain gauges can provide a maximum update rate of one image per second. The space-time variability of the RF, in this case, can be studied much more easily.

The rain gauge network can provide rain field images although of a smaller geographical extension. In the following figures only the interpolation within the area defined by the outermost rain gauges has been performed. The available network layout is very much defined by the topographic configuration of this region where there is a very ragged coastline including several wide river mouths. This has prevented the configuration of the network in a square or rectangular shape. This, thus, has hindered the generation of better pictures. The separations between gauges are, on average, of 3-4 km, which should provide a level of detail smaller than those obtained from the radar, nevertheless, the update rate is much faster which should provide information being missed with the radar (Figure 11).

\subsection{Influence of integration time on rain gauge data}

Integration time plays an important role in the characteristics of the data obtained from the rain gauges due to the smoothing effects introduced [26]. Rain rates from the rain gauges have been derived through running-mean filtering over linearly interpolated, accumulated rain [18, 27], as is illustrated in Figure 12. While many studies, mostly in the fields of hydrology or meteorology, use large accumulation times (hours, days, etc.), in the radiocommunication context, a much
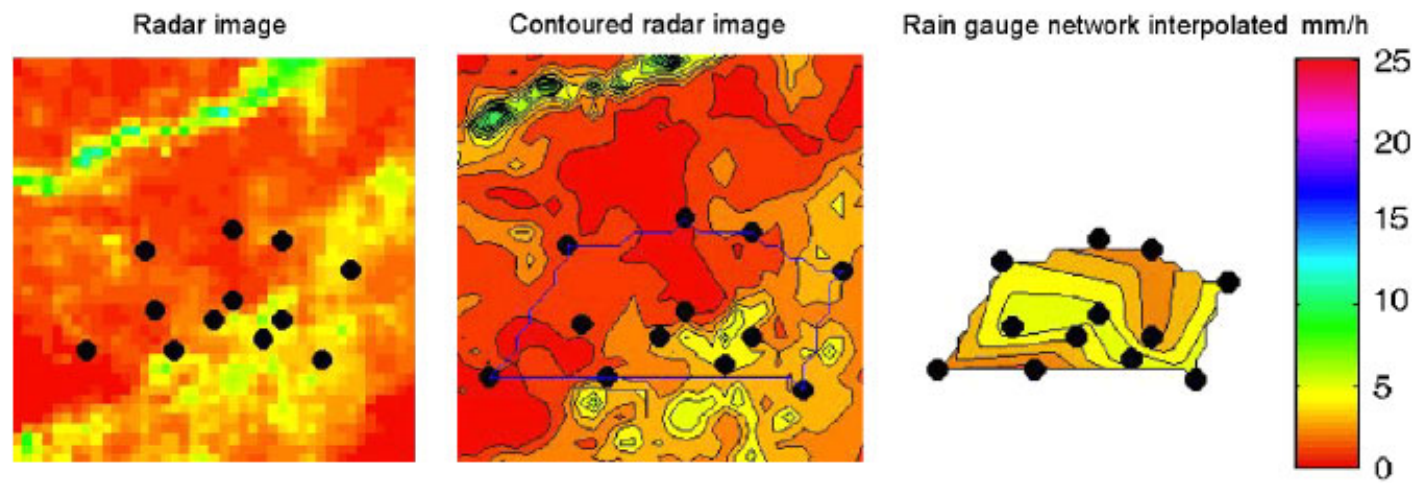

Figure 11. Radar image converted to rain rate, contoured rain radar image and contour plot using rain gauge network data. The locations of the gauges used in this example are represented by black dots. 


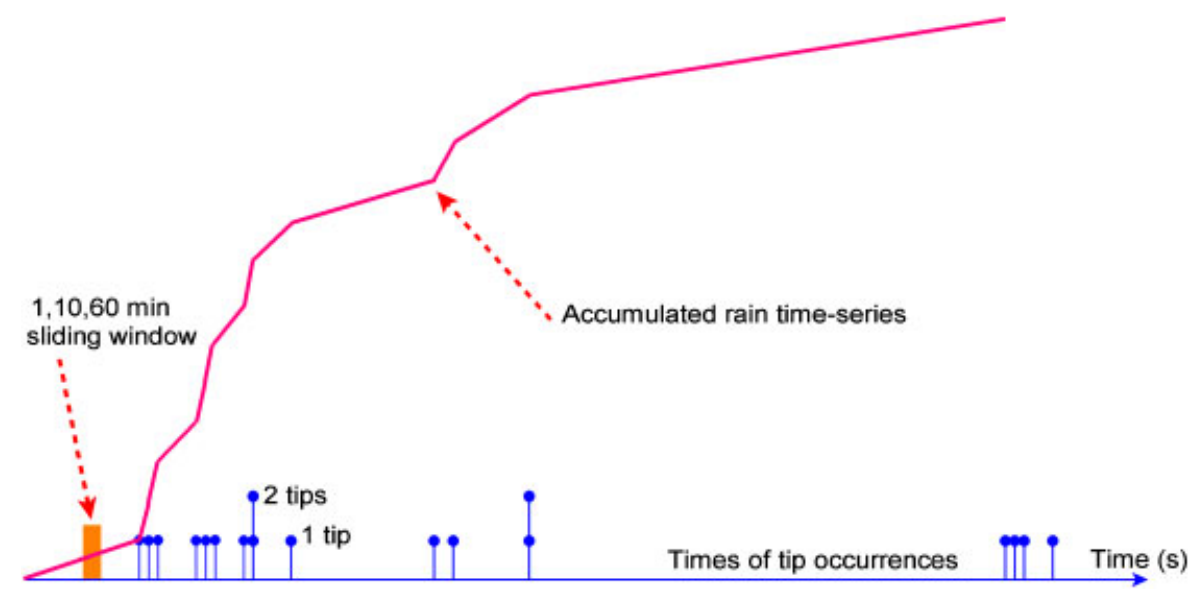

Figure 12. Rain gauge data processing for obtaining rain rates with various integration times $(1,10$, $60 \mathrm{~min})$. The accumulated rain is linearly interpolated and a running-mean filter is applied to the accumulated series.

higher resolution (seconds, a few minutes, etc.), to really estimate the instantaneous rain rate is desirable for linking rain rate to rain-induced radio link attenuation.

Figure 13 illustrates rain rate time-series obtained with the radar for the location corresponding to one of the gauges ( $\mathrm{S} 02)$ and the rain rates derived from this gauge using different integration times. It can be observed how the obtained rain intensity values decrease as the integration time increases. However, the match between radar and rain gauge peak values is very much dependent on the integration time used. It can also be observed how the level of detail in the rain events vanishes as the integration time increases.

Looking into the correlation between radar and the rain gauge derived intensities, the results illustrated in Figure 14(a) have been obtained. In the figure, the average daily cross-correlation coefficients between all rain gauge time-series and the time-series at their equivalent radar pixels have been plotted. The data correspond to 4 months or recordings. It can be observed that the correlation is the maximum for integration times between 10 and $30 \mathrm{~min}$. The same conclusion can be reached if the difference between radar and rain gauge time-series is computed for different integration times as shown in Figure 14(b). In this figure, the average daily RMSE (Root Mean Square Error/Difference) has been plotted for the same data set.

In the following, the results presented correspond to an integration time of $10 \mathrm{~min}$, which is consistent with the $10 \mathrm{~min}$ refresh time of the radar.

\subsection{Comparison between spatial correlation in radar and rain gauges}

The cross-correlations of daily time-series between pairs of rain gauges and between the timeseries corresponding to the rain gauge locations and their radar image equivalent pixels have been calculated and compared to show their similarities and differences. Thus, in Figure 15 four examples of daily cross-correlations between all pairs of gauges $(17 \times 16)$ and between their equivalent radar image pixels have been plotted. The expected result should be such that the identical values would be found for both data sources and, that the overall fitted curve would be a unit-slope straight line. As it is clearly shown in the figures, this is not always the case and a 

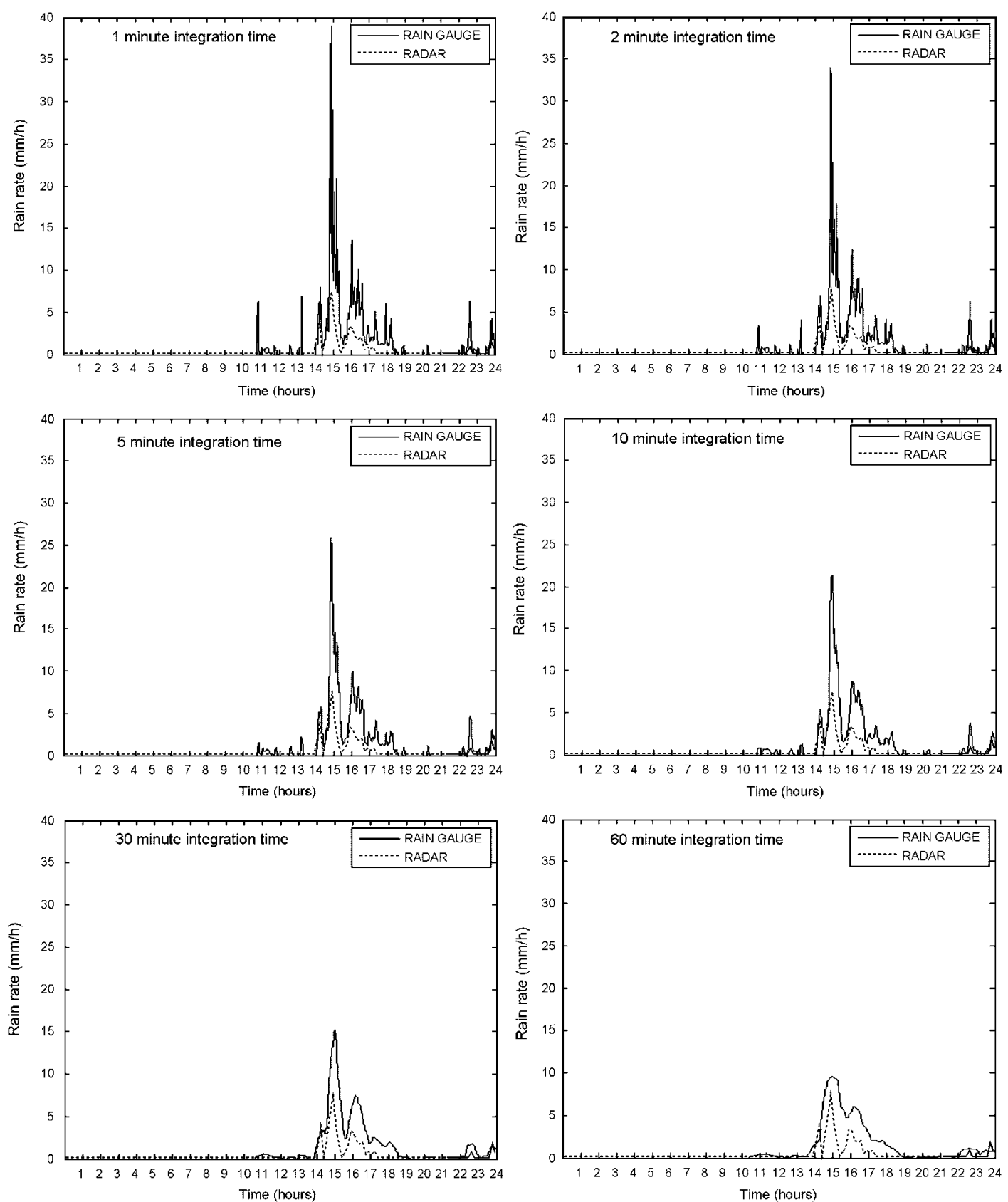

Figure 13. Comparison between radar (dotted line) and rain gauge (solid line) derived rain intensities for different integration times for February 1, 2008 at rain gauge S02. 

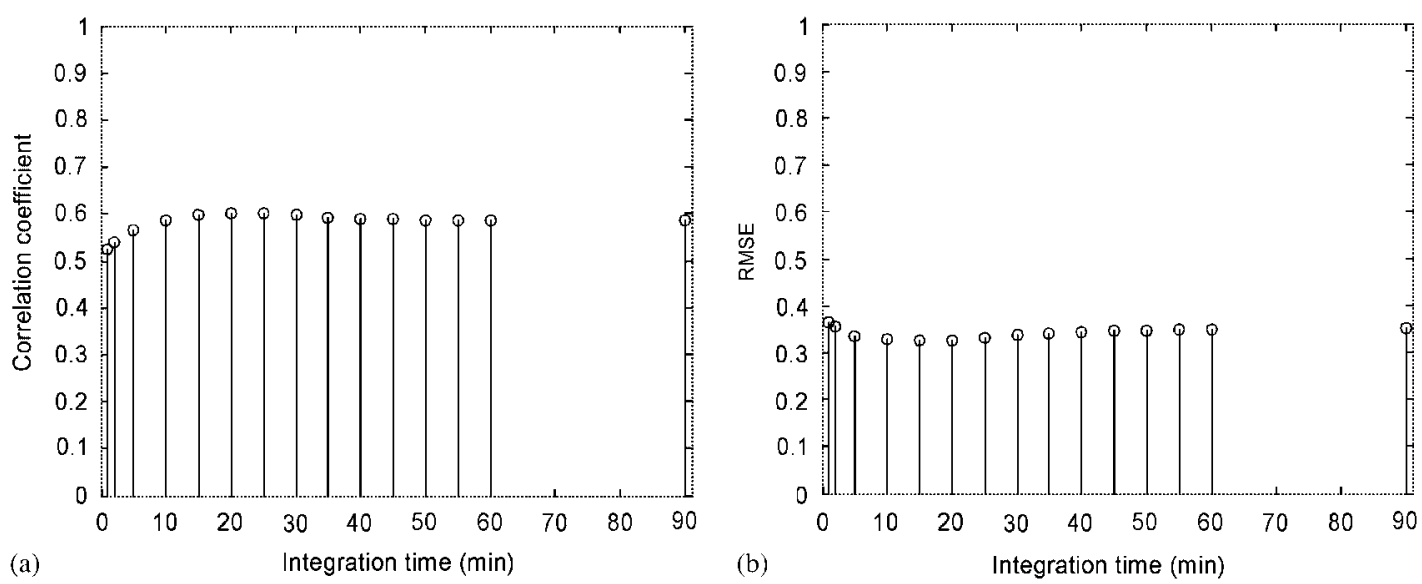

Figure 14. (a) Comparison of the correlation coefficient between data from radar and rain gauges for different integration times. (b) Root mean square error (RMSE) between daily rain time-series from the radar and from a rain gauge.

day-to-day variability is apparent, indicating that the degree of similarity may change depending on the type of rain prevailing during a particular day. These results were obtained by considering a static $z-R$ relationship to convert radar reflectivity data into the rain rate data. A study on the impact of a dynamic radar calibration on this similarity has not been carried out yet. On the other hand, the difference in detail of the two types of measurements has an influence as well.

The effect of the integration time is again studied from a different point of view, and comparisons made between both data sources. Figure 16, corresponding to October 23, 2006, shows how the daily cross-correlation coefficients between rain gauges increase with integration time. The figure also shows how the correlation coefficients decrease with the separation between study points, both for the rain gauges and the radar pixels. An exponential regression fit is also shown for the rain gauge and radar cross-correlations. The negative exponential curves found in the fittings are given in Table I.

\subsection{Advection field estimation using rain gauge data}

We have seen in the previous section that advection information (direction and speed) can be extracted from the radar images. The other possible source of advection information can be the network of rain gauges. To investigate this, the same event has been tracked down at different rain gauge locations and their cross-correlations computed. This allows observing the pass of the event over the surface of the network.

This particular geographical region is located on Spain's Atlantic coast where most rain events show a West or North-West direction. Thus, specific paths through the network have been selected to follow the movement of the rain events. In Figure 17 an approximately West Northwest-East gauge diagonal is shown together with the relative locations of the various gauges and a radar snapshot of an event that took place on February 1, 2008. The particular event illustrated is observed at gauges $\mathrm{S} 02, \mathrm{~S} 15, \mathrm{~S} 07$ and S06 as it progresses over the network (Figure 18). 

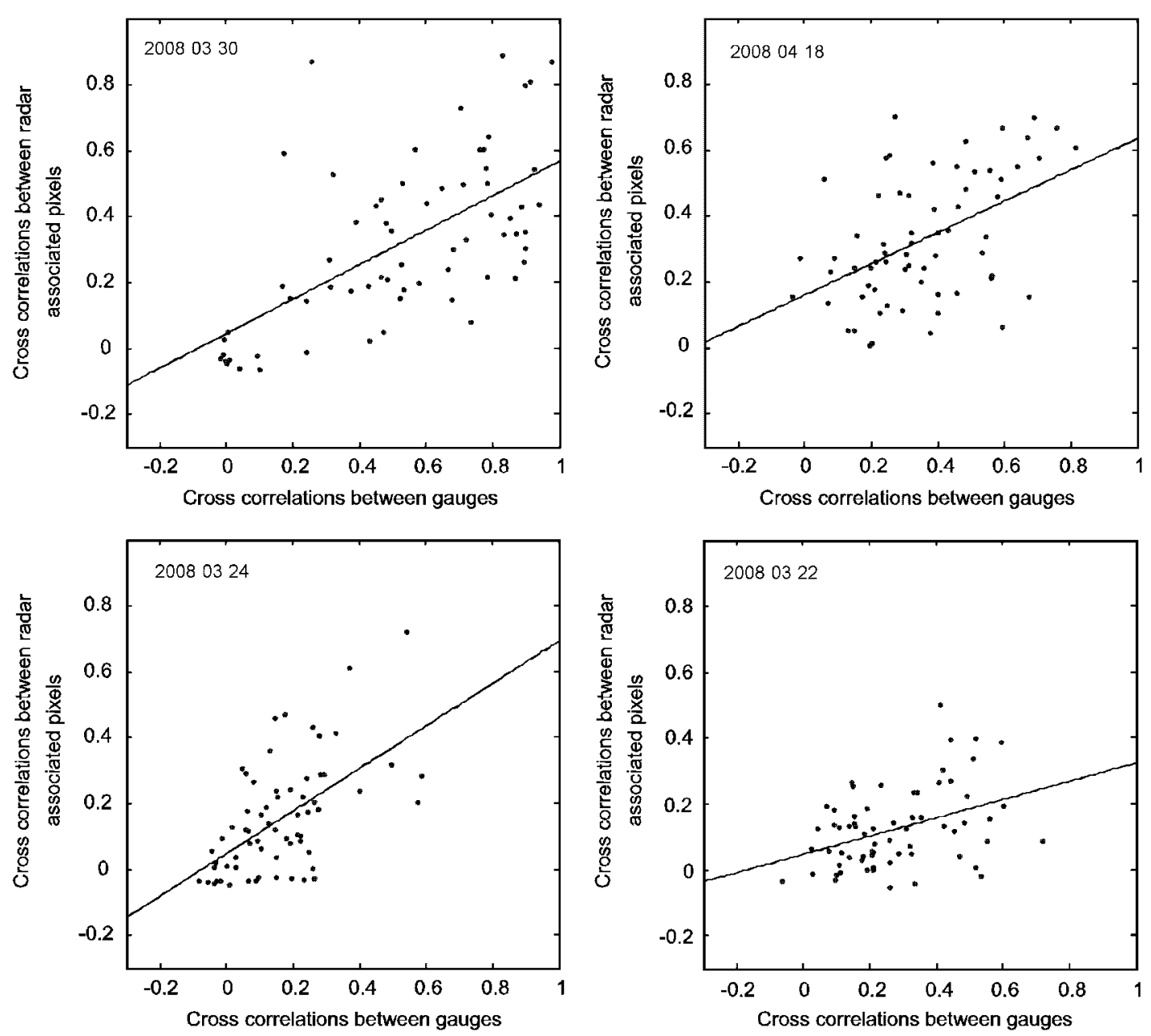

Figure 15. Comparison of daily cross-correlation coefficients between all possible pairs of rain gauges and between their associated radar pixel images using a gauge integration time of 10 min. Days: 20080330 , 200804 18, 20080324 and 200803 22. Solid line shows linear fitting.

Finally, we illustrate how an event can be tracked along a given gauge diagonal and the advection speed extracted. Figure 19 illustrates a closer look at the event as seen at the four gauges of the diagonal in Figure 17. Figure 20 shows all the possible cross-correlations with respect to the first gauge: S02-S02, S02-S015, S02-S07 and S02-S06. It can be clearly shown how the correlation peak is offset with respect to the $\mathrm{S} 02-\mathrm{S} 02$ reference, thus reflects the advance of the event.

Taking into account the times and the separations between gauges, the following velocities have been calculated: $\mathrm{V}_{\mathrm{S} 02-\mathrm{S} 15}=7.56 \mathrm{~km} / \mathrm{h}, \mathrm{V}_{\mathrm{S} 02-\mathrm{S} 07}=14.28 \mathrm{~km} / \mathrm{h}, \mathrm{V}_{\mathrm{S} 02-\mathrm{S} 06}=26.15 \mathrm{~km} / \mathrm{h}$. The average velocity being $16.00 \mathrm{~km} / \mathrm{h}$. These velocities are not the maximum values, only they are components along the specified diagonal. 


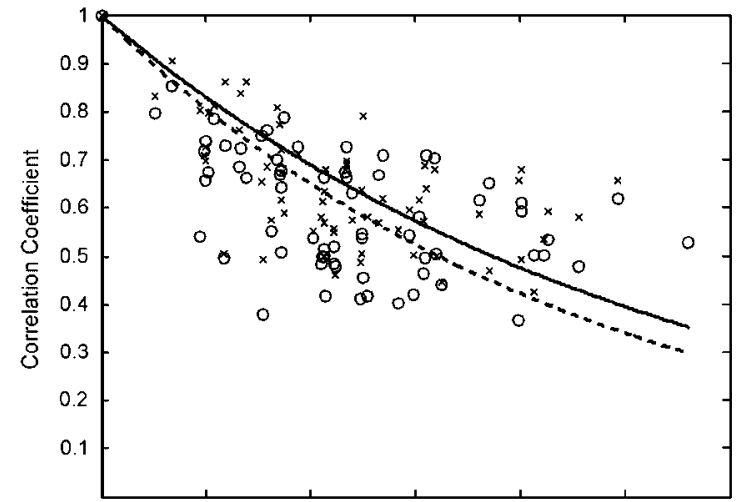

(a)

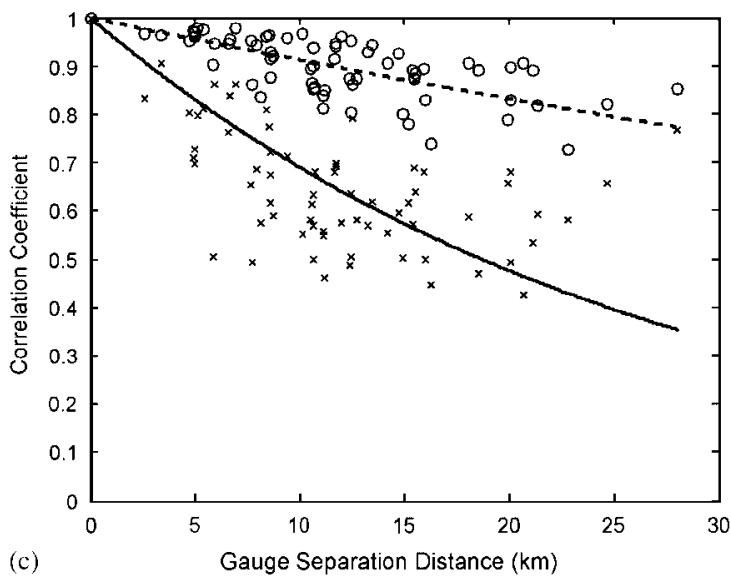

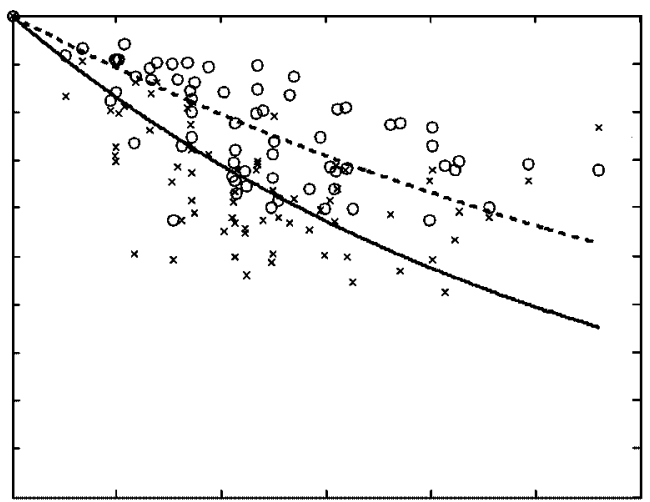

(b)

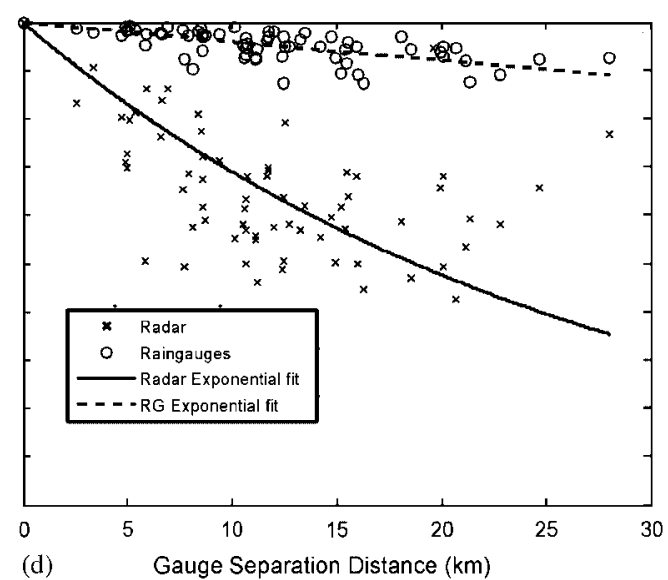

Figure 16. Daily cross-correlations between gauges and between their corresponding radar image pixels for 1, 10 and 60 min gauge integration times (October 23 2006). Associated exponential fits as a function of the distance between locations: (a) 1 min integration time; (b) $10 \mathrm{~min}$ integration time; (c) 30 min integration time; and (d) 60 min integration time.

Table I. Fitting results for the example in Figure 16,

\begin{tabular}{lc}
\multicolumn{2}{c}{$y=\exp (-b x)}$. \\
\hline Data & Parameter $b$ \\
\hline Radar & 0.03711 \\
RG 1 min & 0.04301 \\
RG 10 min & 0.02288 \\
RG 30 min & 0.009175 \\
RG 60 min & 0.004124 \\
\hline
\end{tabular}

\section{CONCLUSIONS}

Current technological developments, especially as we go higher in frequency, give rise to the need for true space-time rain field models for testing the dynamics of fade countermeasures. 


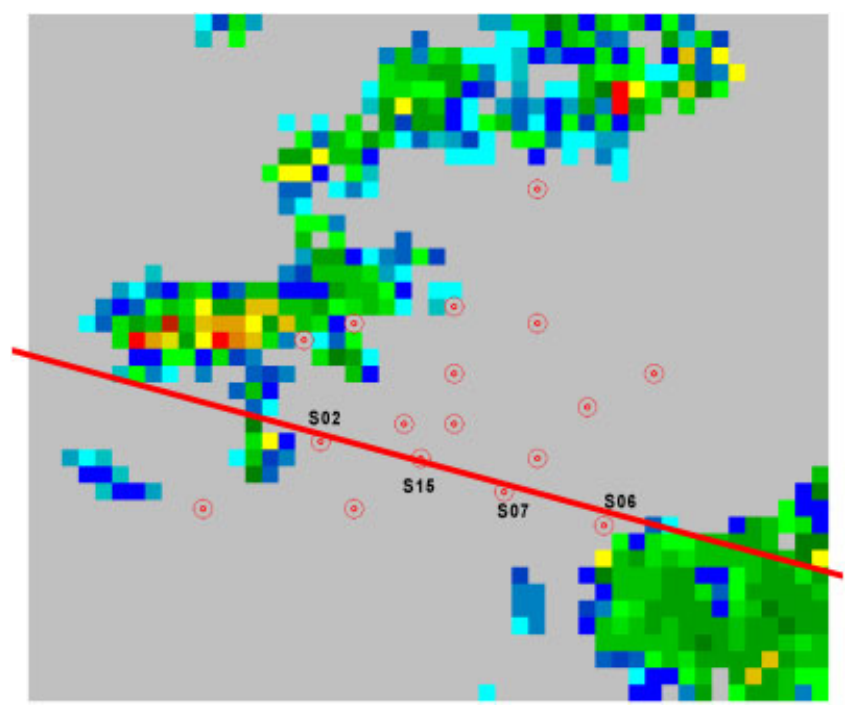

Figure 17. Example of rain gauge diagonal superimposed on a North-West event radar image.
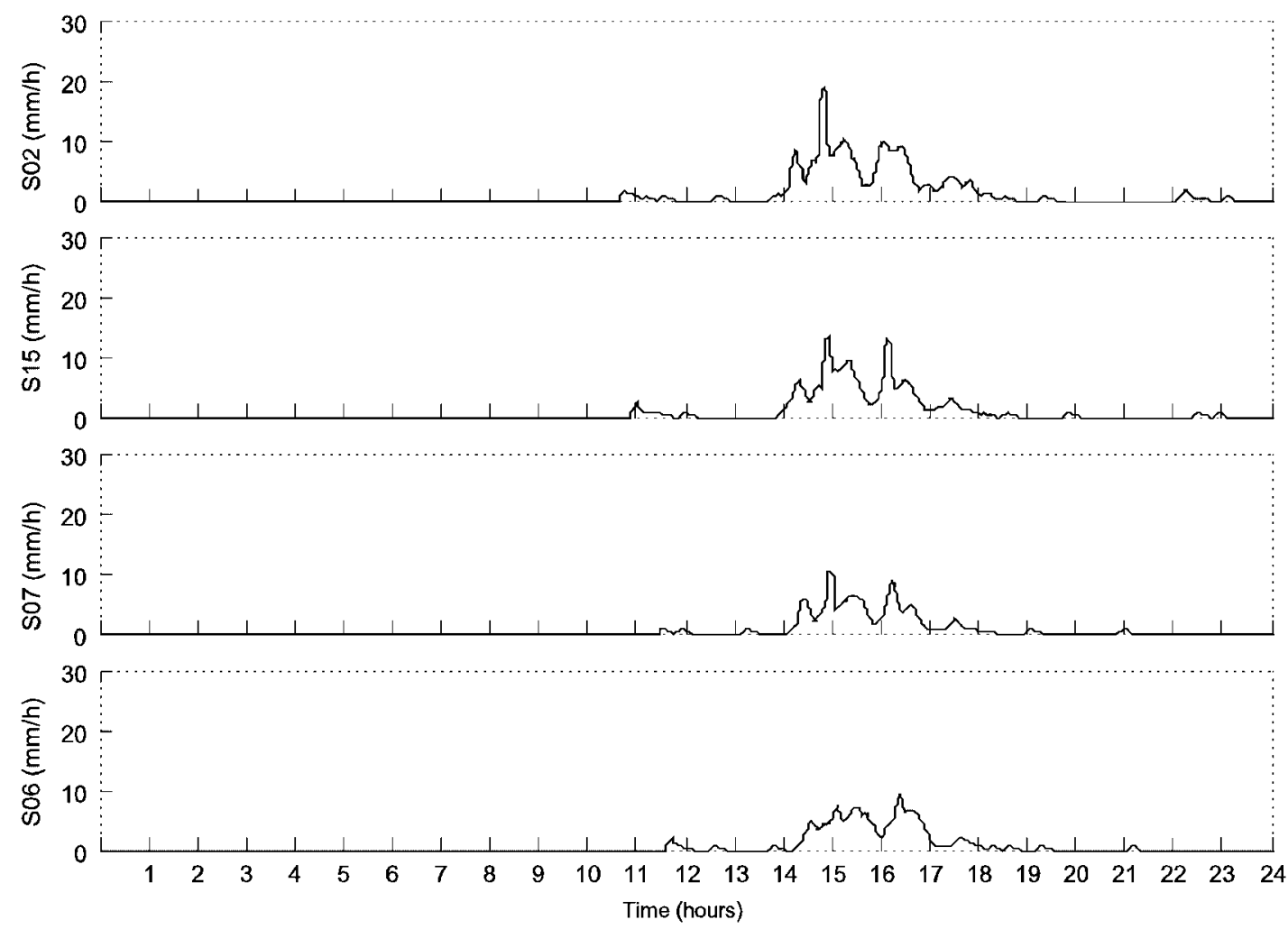

Figure 18. Time evolution of a rain event that took place on February 1, 2008 at various gauges along the diagonal illustrated in Figure 17. 


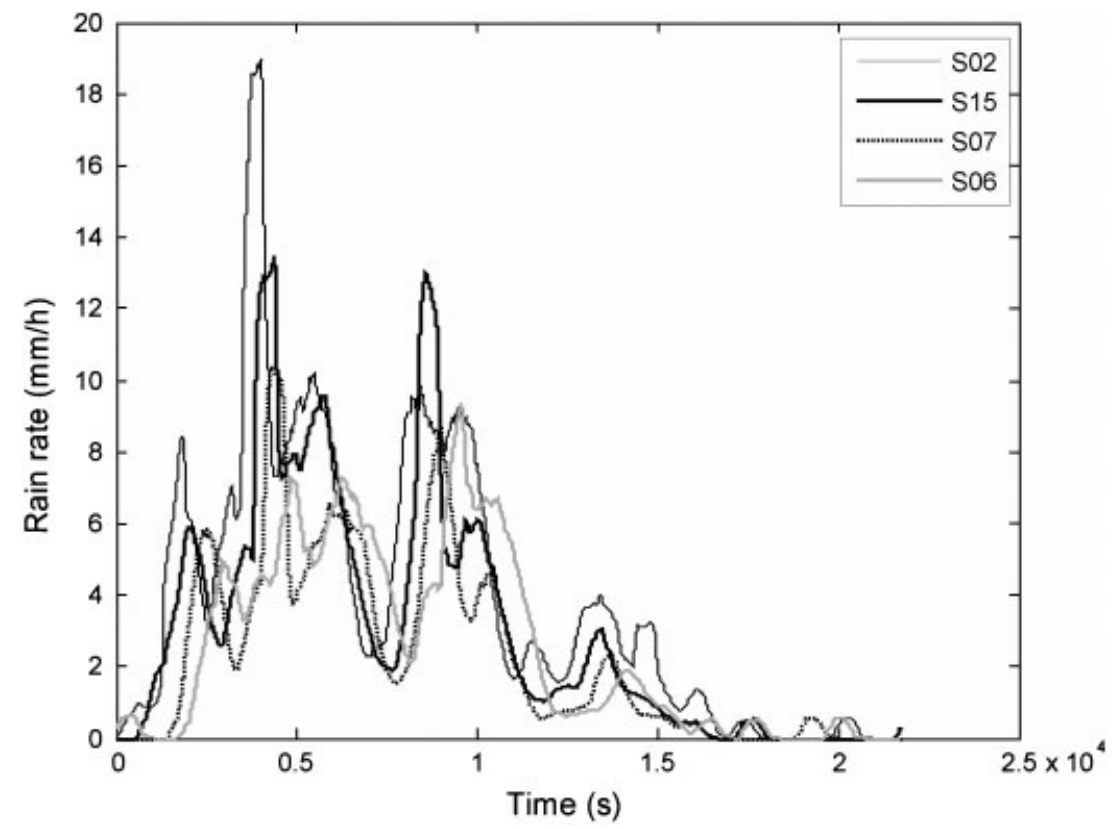

Figure 19. Zoomed in view of the February 1, 2008 event through a chosen gauge diagonal.

There is an important number of spatial models that capture the spatial correlation of rain fields. The most important ones are those based on exponential or Gaussian cells whose numbers and characteristics (peak intensity and radius) are based on well-defined laws reproducing the local annual probability of rain rate. Moreover, realistic fields can be created taking into account inter-cell and inter-cluster distance distributions (e.g., the MultiEXCELL model [5]). However, these fields that faithfully reproduce the existing static characteristics still cannot reproduce the dynamics.

In this paper, we have concentrated on addressing the time domain effects while we have relied on existing spatial rain field models for creating initial fields that are propagated (advected) according to proposed models and assumptions, some of which have been drawn from a combined use of a concurrent weather radar and a network of rain gauges.

Thus, a complete space-time rain rate field model has been presented where an initial rain field created according to the methodology presented by Goldhirsh [17] which, in turn, is based on the EXCELL model [15], is advected according to dynamic, spatially correlated advection fields extracted from the analysis of weather radar images. Experimental data and model fits have been presented as well. Further ideas on how to improve the realism of the generated dynamic fields have also been presented.

Furthermore, the limitations of radar data, especially those related to their limited time resolution, for the required space-time models have been pointed out. These can be overcome by using data from a network of rain gauges. However, it is important to be aware of the similarities and differences between these two sources. A comparative study of these two data sets has also been presented. 


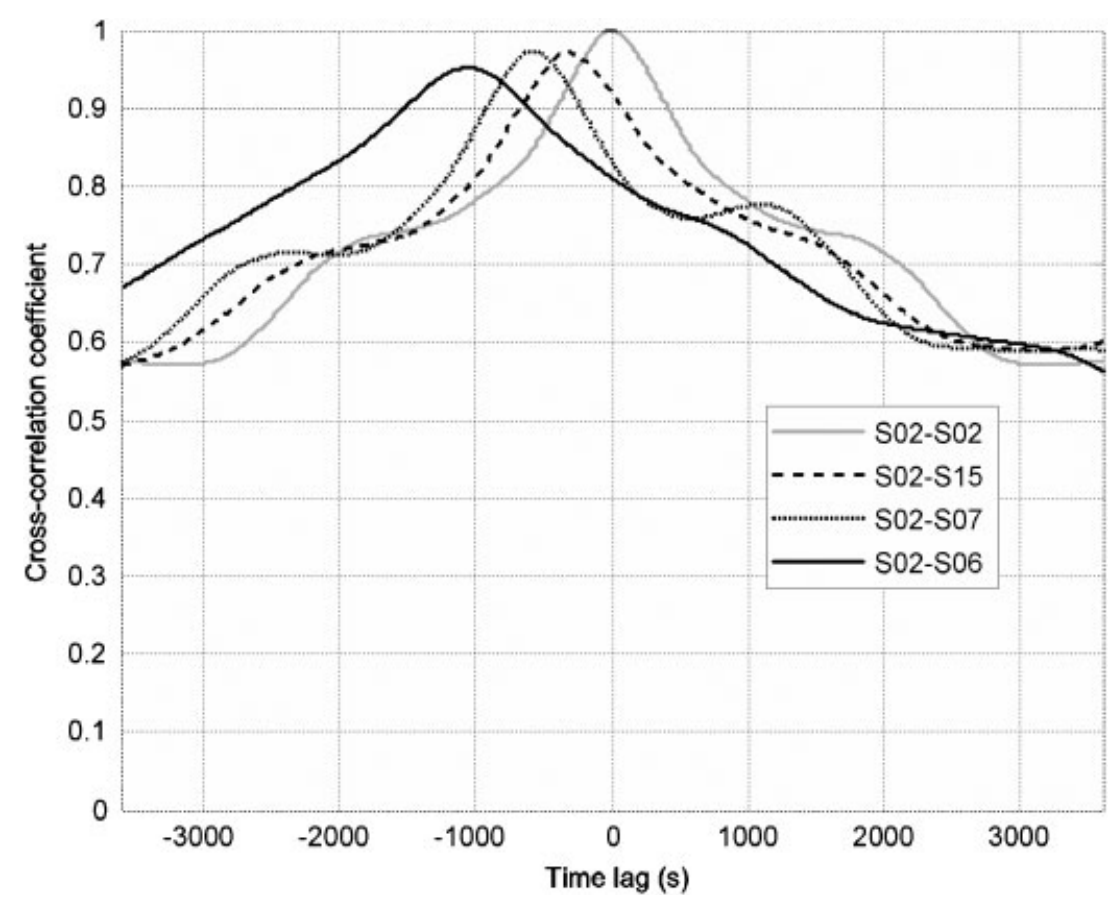

Figure 20. Cross-correlation of an event for February 1, 2008 through a chosen gauge diagonal. The time evolution of the correlation peak can provide an assessment of the advection velocity component along the diagonal.

\section{ACKNOWLEDGEMENTS}

The authors would like to acknowledge the Spanish State Meteorological Agency (AEMET), regional office at Coruña for providing the radar images. This research has been partly carried out in the framework of the European Network of Excellence SatNEx.

\section{REFERENCES}

1. Castanet L, Lemorton J, Bertorelli S, Capsoni C, Lacoste F, Martellucci A. Advanced modelling of the space-time behaviour of the propagation channel for future satcom systems. EuCAP 2006: The First European Conference on Antennas and Propagation, Nice, France, 6-10 November 2006.

2. Jeannin N, Féral L, Sauvageot H, Castanet L, Lemorton J, Lacoste F. Advanced stochastic spatio-temporal modelling of rain attenuation for propagation studies. EuCAP 2007: The Second European Conference on Antennas and Propagation, Edinburgh, U.K., 11-16 November 2007.

3. Borroni L, Capsoni C, Luini L, Riva C. An enhanced version of the SC EXCELL model considering cells movement. EuCAP 2007: The Second European Conference on Antennas and Propagation, Edinburgh, U.K., 11-16 November 2007.

4. Emiliani LD, Paraboni A, Lemorton J, Castanet L, Féral L, Bousquet M. Short- and mid-term prediction techniques of propagation conditions from weather radar observations. Application to resource management in SATCOM systems. IWSSC2006: Satellite and Space Communications, 2006 International Workshop, Leganés, Spain, 14-15 September 2006; 237-241.

5. Luini L. MultiEXCELL: a large-scale rain field model for propagation applications and its experimental identification (Alphasat). Doctoral Dissertation, Politecnico di Milano, Milan, Italy 2009; 1-169. 


\section{COMBINING METEOROLOGICAL RADAR AND NETWORK OF RAIN GAUGES DATA}

6. Wilson JW, Brandes EA. Radar measurement of rainfall-a summary. Bulletin of the American Meteorological Society 1979; 60:1048-1058.

7. Krajewski WF. Cokriging radar-rainfall and rain gage data. Journal of Geophysical Research 1987; 92(D8):9571-9580.

8. Creutin JD, Delrieu G, Lebel T. Rain measurement by rain gauge-radar combination: a geostatistical approach. Journal of Atmospheric and Oceanic Technology 1988; 5:102-115.

9. Seo D-J. Real-time estimation of rainfall fields using radar rainfall and rain gage data. Journal of Hydrology 1998; 208(1-2):37-52.

10. Todini E. A Bayesian technique for conditioning radar precipitation estimates to rain-gauge measurements. Hydrology and Earth System Sciences 2001; 5(2):187-199.

11. Sinclair S, Pegram GGS. Combining radar and rain gauge rainfall estimates using conditional merging. Atmospheric Science Letters 2005; 6(1):19-22.

12. Brommundt $\mathbf{J}$, Bárdossy A. Spatial correlation of radar and gauge precipitation data in high temporal resolution. Advanced Geosciences 2007; 10:103-109.

13. Velasco-Forero CA, Sempere-Torres D, Cassiraga EF, Gómez-Hernández JJ. A non-parametric automatic blending methodology to estimate rainfall fields. Advances in Water Resources 2009; 32(7):969-1120.

14. Núñez A, Pastoriza V, Mariño P, Fontán FP, Fiebig U-C. A space-time model for reproducing rain field dynamics. EuCAP 2007: The Second European Conference on Antennas and Propagation, Edinburgh, U.K., 11-16 November 2007.

15. Capsoni C, Fedi F, Magistroni C, Paraboni A, Pawlina A. Data and theory for a new model of the horizontal structure of rain cells for propagation applications. Radio Science 1987; 22(3):395-404.

16. Féral L, Sauvageot H, Castanet L, Lemorton J. HYCELL - a new hybrid model of the rain horizontal distribution for propagation studies: 1. Modeling of the rain cell. Radio Science 2003; 38(3):1056.

17. Goldhirsh J. Two-dimension visualization of rain cell structures. Radio Science 2000; 35(3):713-729.

18. Fontan FP, Nuñez A, Fiebig U, Machado F, Mariño P. A synthetic rain rate time series generator: a step toward a full space-time model. Radio Science 2007; 42:RS3027. DOI:10.1029/2006RS003520.

19. Willems P. Stochastic generation of spatial rainfall for urban areas. Water Science and Technology 1999; 39(9):23-30.

20. Willems P. A spatial rainfall generator for small spatial scales. Journal of Hydrology 2001; 252(1-4):126-144.

21. De Lannoy GJM, Verhoest NEC, De Troch FP. Characteristics of rainstorms over a temperate region derived from multiple time series of weather radar images. Journal of Hydrology 2005; 307(1-4):126-144.

22. Pastoriza V. Space-time modeling for the simulation and nowcasting of rain fields through image processing techniques of radar data (In Spanish). PhD Thesis, University of Vigo, Vigo, Spain, 2008; 1-134.

23. Bowler NEH, Pierce CE, Seed A. Development of a precipitation nowcasting algorithm based upon optical flow techniques. Journal of Hydrology 2004; 288:74-91.

24. Farnebäck G. Polynomial Expansion for Orientation and Motion Estimation. PhD Thesis, Linköping University, Linköping, Sweden, Dissertation Number 720, 2002; 1-182. Available from: http://lmi.bwh.harvard.edu/papers/ papers/farneback02.html.

25. Smith JA, Krajewski WF. A modeling study of rainfall rate-reflectivity relationships. Water Resources Research 1993; 29:2505-2514.

26. Zawadzki I. On radar-raingauge comparison. Journal of Applied Meteorology 1975; 14:1430-1436.

27. Fiser O. On the tipping-bucket measurement applied to microwave propagation (theory and actual results). Proceedings of the URSI Commission F Open Symposium on Propagation and Remote Sensing, GarmischPartenkirchen, Germany, February 2002.

\section{AUTHORS' BIOGRAPHIES}

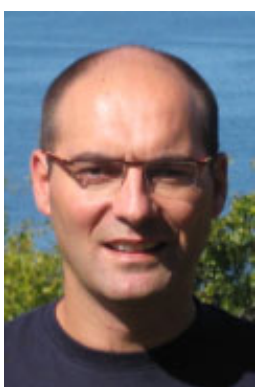

Vicente Pastoriza was born in Bueu, Pontevedra, Spain, in 1972. He received the MS degree in Industrial Engineering and the $\mathrm{PhD}$ degree from the University of Vigo, Vigo, Spain, in 1998 and 2008, respectively. In 2000 he joined, as an Associate Professor in the Electronic Technology Department, University of Vigo, where, since 2004, he has been an Assistant Professor. He is an IEEE Member (M'09).

$\mathrm{He}$ is currently a researcher with the Digital Communications and Instrumentation Group (TE3), University of Vigo. His main research activities are in the fields of atmospheric propagation in radiocommunication systems, signal processing, and computational intelligence and their application in decision making and system modeling. 


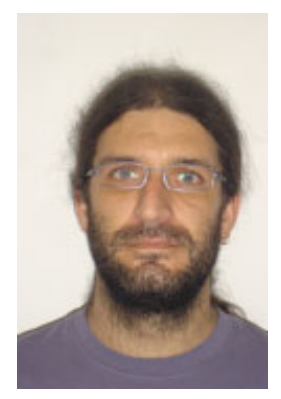

Adolfo Núñez Fernández was born in Vigo, Spain, in 1975. He studies Mathematics at the University of Santiago de Compostela (USC), Spain. Since 2003 he has been working in channel modelling for satellite communications in the Signal Theory and Communications department of the Telecommunications Engineering School of the University of Vigo, Spain. In 2004 he was a guest researcher at the Institute of Communications and Navigation at DLR (German Aerospace Research), Oberpfaffenhofen, Germany.

His current research interests are channel modelling for satellite and mobile radio links.

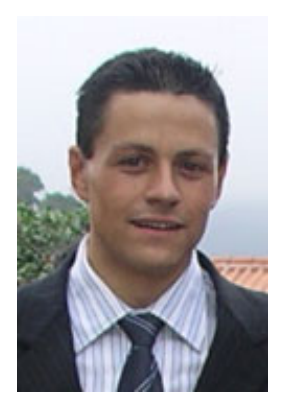

Fernando Machado obtained his MS degree in Telecommunications Engineering in 2000 from the University of Vigo, Vigo, Spain, and his PhD in 2008 from the same university. In 2001 he became an Assistant Professor in the Electronic Technology Department, University of Vigo. Since 2009, he has been a Senior Lecturer in the same department.

He is currently a researcher with the Digital Communications and Instrumentation Group (TE3), University of Vigo. His main research interests include distributed electronic instrumentation, multisensor networks, wireless communications, and radiocommunication systems.

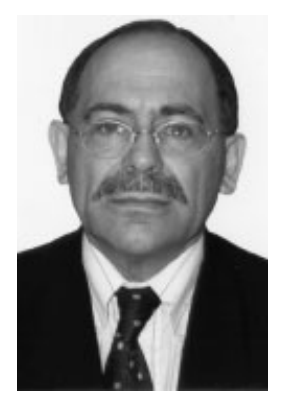

Perfecto Mariño received the $\mathrm{PhD}$ degree in Telecommunications Engineering from the Polytechnic University of Madrid, Spain, in 1984. From 1978 to 1993 he was Associate Professor in the Electronic Technology Department, University of Vigo, Spain. In 1988 he was a Visiting Scientist in the Computer Science Department, Carnegie Mellon University, Pittsburgh, PA, U.S.A. Since 1993 he has been a Full Professor in the Electronic Technology Department, University of Vigo.

His main research interests include distributed electronic instrumentation, wireless sensor networks, fieldbus technology for industrial control, and artificial vision. He has authored more than 20 articles in national and international technical journals, coauthored 12 books and published more than 100 papers in international conferences. He was technical co-chair for international conferences such as IECON, ISIE, SIECI, CAIP, CONTROLO, SAAEI, and evaluator of several journals such as Mechatronics, IEEE Industrial Electronics, IEEE Industrial Informatics, CIT, ESIME, Elsevier and others. $\mathrm{He}$ was involved in more than 40 research and applied projects for several national enterprises such as CITROEN, TELEVES, ENCE, UNION FENOSA, ANFACO, CASTROSUA and others. He holds a European patent on distributed instrumentation for power transformers (2005). He is also the Director of the Digital Communications Division from the Electronic Technology Department, University of Vigo. He has been distinguished as an Expert on Information Technology from the Commission of the European Union for the SPRINT (Luxembourg 1991), COPERNICUS (Brussels 1994) and ACTS (Brussels 2002) programs. $\mathrm{He}$ has served as General Manager of Information Society (2002-2004) and Communications Technology (2002-2006) programs from the State R\&D Office (Autonomous Government, Galicia, Spain) and is also an expert from the R\&D National Program (Ministry of Education and Science, Madrid) in the evaluation of research projects in the field of information and communication technologies. He is an IEEE Senior member. 


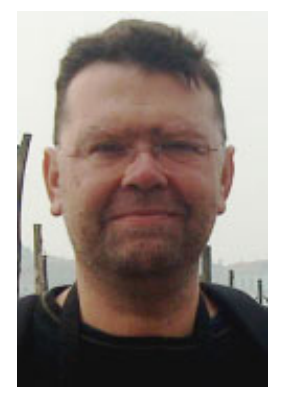

Fernando Pérez Fontán was born in Villagarcía de Arosa, Spain. He received his diploma in Telecommunications Engineering from the Technical University of Madrid in 1982 and his $\mathrm{PhD}$ in 1992 from the same university. He is a full professor with the Telecommunications Engineering School (University of Vigo). He is the author of a number of international magazine and conference papers.

His main research interest is in the field of mobile fixed radiocommunication propagation channel modeling.

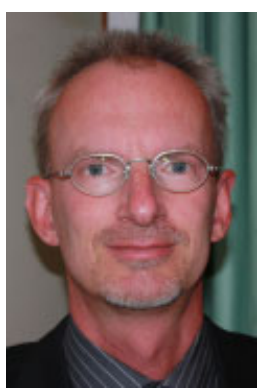

Uwe-Carsten Fiebig was born in Augsburg, Germany, in 1962. He studied Electrical Engineering at the Technical University of Munich (TUM), Germany, and spent the last year of his studies at Ecole Supérieure en Electrotechnique et Electronique in Paris, France. In 1987 he received the Dipl.-Ing. degree from TUM and in 1993 the Dr.-Ing. degree from the University of Kaiserslautern, Germany. Mr. Fiebig joined the Institute of Communications and Navigation at DLR (German Aerospace Research), Oberpfaffenhofen, Germany, in 1988. In 1995 and 1996 he was a guest scientist at the Communications Research Center, Ottawa, Canada, and at the Yokohama National University, Japan, respectively. Since 1998 Mr. Fiebig has been Head of the Department of Communications Systems which carries out research in aeronautical communications, navigation, and mobile radio.

His current research interests include channel modeling for satellite, aeronautical, and mobile radio links. He teaches satellite communications and navigation at the University of Ulm, Germany, and at the University of Linz, Austria. 